\title{
White Matter Hyperintensities in Older Adults and Motoric Cognitive Risk Syndrome
}

Joanna L. Mergeche ${ }^{1}$, Joe Verghese ${ }^{1,2}$, Gilles Allali ${ }^{1,3}$, Cuiling Wang ${ }^{4}$, Olivier Beauchet ${ }^{5}$, V.G. Pradeep Kumar ${ }^{6}$, P.S. Mathuranath ${ }^{7}$, Jennifer Yuan ${ }^{1}$ and Helena M. Blumen ${ }^{1,2^{*}}$

\author{
${ }^{1}$ Department of Neurology, Albert Einstein College of Medicine, Bronx, NY 10461, USA \\ ${ }^{2}$ Department of Medicine, Albert Einstein College of Medicine, Bronx, NY 10461, USA \\ ${ }^{3}$ Department of Clinical Neurosciences, Geneva University Hospitals, Geneva, Switzerland \\ ${ }^{4}$ Departments of Epidemiology, Albert Einstein College of Medicine, Bronx, NY 10461, USA \\ ${ }^{5}$ Department of Neurosciences, Angers University Hospital, Angers, France \\ ${ }^{6}$ Department of Neurology, Baby Memorial Hospital, Kozhikode, Kerala, India \\ ${ }^{7}$ Department of Neurology, National Institute of Mental Health $\Xi^{2}$ Neurosciences, Bengaluru, Karnataka, India
}

\section{Correspondence to:}

Helena M. Blumen, PhD

Departments of Medicine and Neurology

Albert Einstein College of Medicine

1225 Morris Park Avenue Room 313B

Bronx, NY 10461, USA

Tel: 718-430-3810

Fax: 718-430-3829

E-mail: helena.blumen@einstein.yu.edu

Received: August 17, 2016

Accepted: November 01, 2016

Published: November 03, 2016

Citation: Mergeche JL, Verghese J, Allali G, Wang C, Beauchet O, et al. 2016. White Matter Hyperintensities in Older Adults and Motoric Cognitive Risk Syndrome. I Neuroimaging Psychiatry Neurol 1(2): 73-78.

Copyright: (C) 2016 Mergeche et al. This is an Open Access article distributed under the terms of the Creative Commons Attribution 4.0 International License (CC-BY) (http:// creativecommons.org/licenses/by/4.0/) which permits commercial use, including reproduction, adaptation, and distribution of the article provided the original author and source are credited.

Published by United Scientific Group

\begin{abstract}
Introduction: Motoric cognitive risk (MCR) syndrome is a recently described pre-dementia syndrome characterized by slow gait and cognitive complaints that has been implicated as a predictor of cognitive decline and dementia in older adults. Previous work suggests that cerebrovascular disease is associated with MCR. White matter hyperintensities (WMH) are postulated to be a product of cerebrovascular disease, and have been associated with impaired mobility and impaired cognition. This study aimed to determine if MCR is associated with regional WMH.
\end{abstract}

Methods: Two cross-cultural cohorts of non-demented older adults were examined: 174 from a French memory clinic $(62.1 \%$ male, mean age $70.7 \pm$ 4.3 years) and 184 from an Indian community-dwelling cohort (55.4\% male, mean age $66.2 \pm 5.2$ years). Participants were evaluated for slow gait, cognitive complaints, and regional WMH via MRI (fluid attenuated inversion recovery) FLAIR sequence.

Results: Overall, $20.7 \%$ of participants met criteria for MCR, and $72.9 \%$ of participants had WMH on FLAIR. WMH in the frontal, parieto-occipital, temporal, basal ganglia, cerebellum, or brainstem were not associated with MCR in either of the two cohorts.

Conclusion:WMH was not significantly associated with MCR in this studied sample of participants, suggesting that other cerebrovascular pathophysiological mechanisms, or combination of mechanisms, might underlie MCR.

\section{Keywords}

White matter hyperintensities, Motoric cognitive risk, Gait, Cognition, Cerebrovascular disease, Vascular injury

\section{Abbreviations}

FLAIR: Fluid attenuated inversion recovery; MCR: Motoric cognitive risk; WMH: White matter hyperintensities 


\section{Introduction}

Motoric cognitive risk (MCR) syndrome is a recently described pre-dementia syndrome characterized by slow gait and cognitive complaints [1-3]. MCR has been implicated as a predictor of cognitive decline and dementia in older adults and has been associated with increased mortality $[2,4]$. MCR can be easily assessed in a variety of clinical settings without complex or extensive testing. As such, MCR allows for optimized assessment of dementia risk, initiation of early preventative measures, reduced healthcare costs, and potentially reduced mortality [4-6].

MCR has been shown to predict both Alzheimer's disease [3] and vascular dementia [1] in previous cohort studies. Cerebrovascular disease is a clear contributor to vascular dementia, but has also been implicated in the pathogenesis of Alzheimer's dementia [7]. MCR and cerebrovascular disease share many risk factors such as age, hypertension, and diabetes [3, 8-13]. A previous study evaluated regional lacunar infarcts and cortical microbleeds as measures of cerebral small vessel disease in the context of MCR [14] frontal lacunar infarcts were associated with MCR while cortical micro bleeds were not associated with MCR in this study. These findings suggest that specific types of regional cerebrovascular injury might contribute to the evolution of MCR.

White matter hyperintensities (WMH) are areas with high signal intensities on fluid attenuated inversion recovery (FLAIR) magnetic resonance images. WMH are ubiquitous in aging populations and have often been regarded as non-specific. The pathophysiological evolution of $\mathrm{WMH}$ is hypothesized to be a product of cerebrovascular disease and reduced vascular integrity $[15,16]$. Risk factors for cerebrovascular disease, such as hypertension, diabetes, and aging, have been associated with the development of WMH $[17,18]$. WMH are associated with many clinical consequences like impaired mobility and impaired cognition [19-22]. Rosario et al. found that microstructural integrity is a moderating factor in the association between WMH and gait [23]. Two studies identified associations between regional $\mathrm{WMH}$ and mild cognitive impairment syndrome, another predementia syndrome $[18,24]$. Interestingly, cerebral blood flow studies support that the pathogenesis and clinical presentation of WMH vary depending on the topographic location of the $\mathrm{WMH}$ in the brain [25].

No studies have assessed whether regional WMH, as a measure of cerebrovascular disease, are associated with MCR. Considering previous work suggesting that MCR is predictive of vascular dementia $[1,26]$, that cerebrovascular disease shares common risk factors with $\mathrm{MCR}$ and $\mathrm{WMH}[1,3]$, and that regional $\mathrm{WMH}$ have cognitive consequences [3, 4, 20,21], we hypothesized that MCR would be associated with regional WMH perhaps in the frontal region, as found previously for lacunar infarcts [14]. In this study, we evaluate whether MCR is associated with regional WMH in two large cohorts of nondemented older adults from a developed country, France, and lower-middle income country, India.

\section{Materials and Methods}

\section{Participants}

Participants were recruited from two independent studies in a developed country, France, and lower-middle income country, India. These two cohorts were chosen for this analysis as they had previously participated in MCR collaborative studies [3, 14, 27, 28], have neuroimaging available, and previous studies have indicated that there may be differences in prevalence of cerebrovascular disease by country and ethnicity [29-31]. The French cohort $(\mathrm{N}=174)$ was obtained from a memory clinic population at Angers University Hospital; they were recruited in the Gait and Alzheimer Interactions Tracking study, an ongoing cross-sectional study in France. The Indian cohort $(\mathrm{N}=184)$ is a community-dwelling cohort from the Kerala-Einstein study [14, 27, 28], and was recruited from Neurology clinics at Baby Memorial Hospital in Kozhikode in the southern Indian state of Kerala. All 358 participants were $>60$ years of age, were non-demented [27], and had complete quantitative gait measurements, cognitive complaint data, neurologic examination, and FLAIR imaging. Exclusion criteria were history of dementia, presence of severe audiovisual disturbances, severe medical or neurological disease, and standard MRI exclusion criteria, as previously described [27].

Written informed consent was obtained from all participants. The parent studies received approval from their local institutional review boards. The Albert Einstein College of Medicine Institutional Review Board (Bronx, NY, USA) approved this analysis.

\section{Motoric cognitive risk syndrome (MCR)}

MCR is defined by slow gait and cognitive complaints in the absence of dementia and mobility disability, as previously described [1,3]. Cognitive complaints were elicited from participants in clinician interviews and from standardized questionnaires [32-34]. Slow gait was defined as walking speed one standard deviation below the age- and sex-adjusted means during normal pace walking condition. These adjusted means were previously established in each cohort [3]. The slow gait threshold scores in the Indian cohort were: males $<75$ years at $79.08 \mathrm{~cm} / \mathrm{s}$, males $>75$ years at $54.55 \mathrm{~cm} / \mathrm{s}$, females $<75$ years at $72.00 \mathrm{~cm} / \mathrm{s}$, and females $>75$ years at $44.45 \mathrm{~cm} / \mathrm{s}$. The slow gait threshold scores in the French cohort were: males $<75$ years at $94.09 \mathrm{~cm} / \mathrm{s}$, males $>75$ years at $84.26 \mathrm{~cm} / \mathrm{s}$, females $<75$ years at $92.02 \mathrm{~cm} / \mathrm{s}$, and females $>75$ years at $74.66 \mathrm{~cm} / \mathrm{s}$. Gait speed was measured quantitatively with a computerized walkway with embedded pressure sensors (GAITRite, CIR systems, Havertown, PA, USA) for all participants in the French cohort and for 149 participants of the Indian cohort [35]. In the Indian cohort, 35 participants had gait speed measured over a fixed distance, and then converted to centimeters per second $[1,3,36]$. Dementia was diagnosed at consensus case conferences in both cohorts using established criteria. See mobility disability criteria in previous papers [2]. If participants met criteria for both slow gait and cognitive complaint, and did not have dementia or mobility disability, they were designated as having MCR. 


\section{Fluid attenuated inversion recovery (FLAIR)}

Participants underwent a standard cerebral MRI protocol including a FLAIR sequence. FLAIR sequences are particularly sensitive to WMH as they mask the cerebrospinal fluid that can otherwise cloud other MRI images and findings. Images were acquired in France (University of Angers Hospital in Angers) and India (Baby Memorial Hospital in Kerala) and sent to Albert Einstein College of Medicine (Bronx, NY, USA) for image rating and analysis. Imaging was performed at both sites with a 1.5-Tesla MRI scanner (Magnetom Avanto, Siemens Medical Solutions, Erlangen, Germany) using a standard MRI protocol including FLAIR images (acquisition matrix $=256 \times 232, \mathrm{FOV}=240 \mathrm{~mm} \times 180 \mathrm{~mm}$, resolution $=5$ $\mathrm{mm}$, gap $=0.5 \mathrm{~mm}, 30$ slices, TE $/ \mathrm{TR} / \mathrm{TI}=122 \mathrm{~ms} / 9000 \mathrm{~ms} /$ $2500 \mathrm{~ms})$.

\section{White matter hyperintensities ratings}

FLAIR images were rated using the well-established rating scale for WMH derived by Wahlund and colleagues [37]. Ratings were made for six brain regions: frontal, parietooccipital, temporal, basal ganglia, cerebellum, and brainstem. Bilateral ratings were obtained for all regions except for the brainstem, which was rated as one region given its small size and difficulty of establishing laterality for medial lesions. In the frontal, parieto-occipital, temporal, cerebellum, and brainstem regions, focal lesions $>2 \mathrm{~mm}$ were rated a 1 , confluent lesions were rated a 2 , and diffuse involvement of the entire region was rated a 3 . In the basal ganglia, focal lesions $\geq 5 \mathrm{~mm}$ were rated a $1,>1$ focal lesion was rated a 2 , and confluent lesions were rated a 3. Regional WMH ratings were analyzed as binomial data: present (inclusive of focal, confluent, and diffuse WMH) or absent. Two raters, blinded to clinical information and MCR status performed all WMH ratings (J.L.M, $\mathrm{N}=322$ and J.Y., $\mathrm{N}=26$ ). Inter-rater reliability was calculated between the raters and a board-certified neurologist (G.A.) and a boardcertified radiologist (C.K.) for a subset of images (J.L.M., $\kappa=$ 0.78 for 30 images and J.Y., $\kappa=0.67$ for 16 images, indicating adequate agreement according to conventional guidelines of inter-rater agreement [38]). Strokes detected on FLAIR were confirmed with the board-certified neurologist.

\section{Covariates}

Participant characteristics were obtained from the independent studies and included age, sex, years of education, history of stroke and/or stroke on MRI, diabetes, and hypertension. Smoking history was only collected in the Indian cohort. Body mass index (BMI) was only collected in the French cohort.

\section{Statistical analyses}

Statistical analyses were performed using JMP 10 software (SAS Institute Inc., Cary, NC,USA) and STAT12 (StataCorp LP, College Station, TX, USA). Cohort characteristics between subjects with and without MCR were compared using Student t-test test for continuous variables, and Fisher exact test or Pearson $\chi^{2}$ tests for categorical variables where appropriate. $\mathrm{P}$-values $\leq .05$ were considered significant.

\section{Results}

\section{Participant characteristics}

Table 1 summarizes participant characteristics in the French and Indian cohorts. The French cohort was significantly older $(70.7 \pm 4.3$ years vs. $66.2 \pm 5.2$ years, $\mathrm{P}<0.001)$, had more education $>13$ years $(24.1 \%$ vs. $6.2 \%, \mathrm{P}<0.001)$, less diabetes (1.7\% vs. $32.6 \%, \mathrm{P}<0.001)$, less hypertension $(30.5 \%$ vs. $63.0 \%$, $\mathrm{P}<0.001)$, and faster gait velocity $(109.4 \pm 20.3 \mathrm{~cm} / \mathrm{s}$ vs. $88.8 \pm$ $22.8 \mathrm{~cm} / \mathrm{s}, \mathrm{P}<0.001)$ than the Indian cohort.

\section{MCR}

The prevalence of MCR in this study was $20.7 \%$. The prevalence of MCR was similar between the French and Indian cohorts: $19.5 \%$ in the French cohort and $21.7 \%$ in the Indian cohort $(P=0.61)$. In the French cohort, participants with and without MCR were comparable in patient characteristics as shown in Table 1 . In the Indian cohort, participants were comparable in all characteristics except that patients with MCR were more likely to be male $(75.0 \%$ vs. $50.0 \%, \mathrm{P}=0.004)$.

Table 1: Participant Characteristics ${ }^{1}$

\begin{tabular}{|c|c|c|c|c|}
\hline & All & No MCR & MCR & P-value ${ }^{2}$ \\
\hline \multicolumn{5}{|l|}{ French Cohort } \\
\hline $\mathrm{N}$ & 174 & 140 & 34 & \\
\hline Age $\mathrm{M} \pm \mathrm{SD}$, years & $70.7 \pm 4.3$ & $70.6 \pm 4.4$ & $71.0 \pm 4.0$ & 0.62 \\
\hline Sex, male & $62.1 \%$ & $60.7 \%$ & $67.7 \%$ & 0.45 \\
\hline Body Mass Index & $26.1 \pm 3.8$ & $25.6 \pm 3.2$ & $28.1 \pm 5.0$ & $<0.001$ \\
\hline Education & & & & 0.28 \\
\hline$\leq 4$ years & $1.7 \%$ & $2.1 \%$ & $0 \%$ & \\
\hline $5-8$ years & $39.1 \%$ & $37.1 \%$ & $47.1 \%$ & \\
\hline $9-12$ years & $35.1 \%$ & $34.3 \%$ & $38.2 \%$ & \\
\hline$\geq 13$ years & $24.1 \%$ & $26.4 \%$ & $14.7 \%$ & \\
\hline Stroke & $4.6 \%$ & $5.0 \%$ & $2.9 \%$ & 0.59 \\
\hline Diabetes & $1.7 \%$ & $2.1 \%$ & $0 \%$ & 0.25 \\
\hline Hypertension & $30.5 \%$ & $29.3 \%$ & $35.3 \%$ & 0.50 \\
\hline Gait Velocity $\mathrm{M} \pm \mathrm{SD}, \mathrm{cm} / \mathrm{s}$ & $109.4 \pm 20.3$ & $116.1 \pm 15.6$ & $81.5 \pm 12.0$ & $<0.001$ \\
\hline \multicolumn{5}{|l|}{ Indian Cohort } \\
\hline $\mathrm{N}$ & 184 & 144 & 40 & \\
\hline Age $\mathrm{M} \pm \mathrm{SD}$, years & $66.2 \pm 5.2$ & $65.9 \pm 5.2$ & $67.4 \pm 4.9$ & 0.09 \\
\hline Sex, male & $55.4 \%$ & $50.0 \%$ & $75.0 \%$ & 0.004 \\
\hline Education & & & & 0.10 \\
\hline$\leq 4$ years & $5.6 \%$ & $7.2 \%$ & $0 \%$ & \\
\hline $5-8$ years & $35.4 \%$ & $25.8 \%$ & $9.6 \%$ & \\
\hline $9-12$ years & $52.8 \%$ & $42.1 \%$ & $10.7 \%$ & \\
\hline$\geq 13$ years & $6.2 \%$ & $4.5 \%$ & $1.7 \%$ & \\
\hline Stroke $^{2}$ & $7.1 \%$ & $5.6 \%$ & $12.5 \%$ & 0.16 \\
\hline Diabetes & $32.6 \%$ & $30.6 \%$ & $40.0 \%$ & 0.27 \\
\hline Hypertension & $63.0 \%$ & $61.1 \%$ & $70.0 \%$ & 0.30 \\
\hline History of Smoking & $19.0 \%$ & $18.8 \%$ & $20.0 \%$ & 0.86 \\
\hline Gait Velocity $\mathrm{M} \pm \mathrm{SD}, \mathrm{cm} / \mathrm{s}$ & $88.8 \pm 22.8$ & $96.2 \pm 19.4$ & $62.0 \pm 11.0$ & $<0.001$ \\
\hline \multicolumn{5}{|c|}{$\begin{array}{l}{ }^{1} \text { Data presented as percentages or mean } \pm \text { standard deviations. } \\
{ }^{2} \text { Student } t \text {-test for continuous variables, and Fisher exact test or Pearson } \\
\chi^{2} \text { tests for categorical variables. }\end{array}$} \\
\hline
\end{tabular}


In the French cohort, patients with MCR had significantly higher BMI $(28.1 \pm 5.0$ vs. $25.6 \pm 3.2, \mathrm{p}<0.001)$.

\section{WMH}

The prevalence of WMH overall in this study was $72.9 \%$. Participants with and without WMH were comparable in terms of sex, education, stroke, diabetes, and hypertension. The French cohort had higher prevalence of WMH overall than the Indian cohort $(77.5 \%$ vs. $68.5 \%, \mathrm{P}=0.05)$. In the pooled sample, participants with WMH were older than participants without $\mathrm{WMH}(69.2 \pm 5.5$ years vs. $66.2 \pm 4.0$ years, $\mathrm{P}<0.001)$.

When evaluating WMH in the context of the components of MCR, there were no significant associations. In the French cohort, $17.0 \%$ of patients with slow gait had WMH vs. $28.2 \%$ of patients without slow gait, $\mathrm{p}=0.13$. In the Indian cohort, $29.4 \%$ of patients with slow gait had WMH vs. $24.2 \%$ of patients without slow gait, $p=0.46$ and $65.9 \%$ of patients with cognitive complaint had WMH vs. $58.6 \%$ without cognitive complaint, $\mathrm{p}=0.35$.

The location of the most prevalent regional $\mathrm{WMH}$ was in the right frontal (French 67.2\% and Indian 60.0\%) and left frontal (French $61.5 \%$ and Indian 56.0\%) regions, as demonstrated in Table 2. The least prevalent regional WMH were in the right cerebellum (French 2.3\% and Indian 0\%) and left cerebellum (French $0.6 \%$ and Indian 2.7\%). There were no significant differences in the prevalence of regional WMH between patients with and without MCR as shown in Table 2. There were no associations between the severity of WMH overall or in specific regions with MCR (data not shown). Figure 1 depicts FLAIR images of WMH in the frontal, parieto-occipital, and temporal regions.

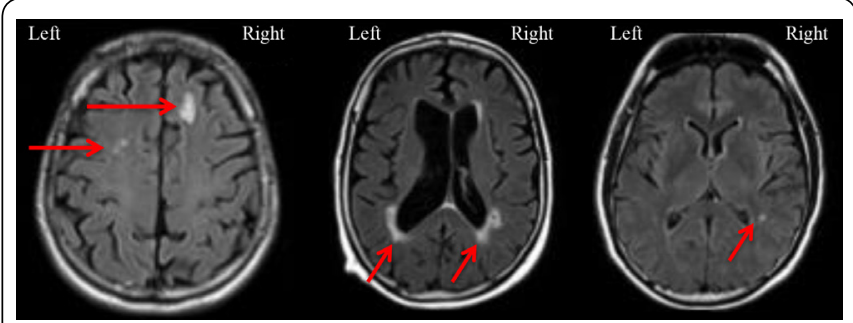

Figure 1: WMH on FLAIR. This figure presents FLAIR image examples of $\mathrm{WMH}$ in the frontal region (top), the parieto-occipital region (middle), and temporal region (bottom). Right and left are indicated for orientation. Red arrows indicating WMH on the images.

\section{Discussion}

This study is the first to evaluate regional WMH in the context of the MCR syndrome in effort to clarify the contribution of cerebrovascular disease and vascular injury to the pathophysiology of MCR. The prevalence of MCR in this study was within the range of previously published MCR studies [1, 2, 4, 14], but higher than the estimated global prevalence [3]. This study also found that BMI was significantly associated with MCR in the French cohort, as demonstrated in previous work [3]. The prevalence of WMH was also consistent with previous studies [14, 22, 24, 39-44]. However, the French cohort did have a higher prevalence of $\mathrm{WMH}$ overall. The higher prevalence of $\mathrm{WMH}$ in the
French cohort might be due to the fact that the cohort was obtained from a memory clinic, which by definition means all of these patients had cognitive complaint. The Indian cohort demonstrates that a greater proportion of patients with cognitive complaint had WMH than patients with slow gait. These findings suggest that perhaps WMH contribute to the individual components of the MCR syndrome, as previously suggested by other studies [19-22], but additional pathology or mechanisms might be required to cross the diagnostic threshold that presents as the MCR syndrome.

The primary finding of this study is that the association of regional WMH with MCR is not statistically significant in this studied sample and that $\mathrm{WMH}$ are rather a ubiquitous finding in non-demented older adults. This finding suggests that vascular mechanisms other than WMH may contribute to the pathophysiology of MCR, as was previously suggested in the case of regional lacunar infarcts [14]. Wang et al. [14] reported that $\mathrm{WMH}$ overall were not associated with MCR and our study replicated these findings. Our study further evaluated this by assessing regional WMH in the context of MCR in two independent cohorts of non-demented older adults.

Cerebrovascular disease and vascular injury are products of different pathophysiological mechanisms. For example, microbleeds are small foci of chronicblood products in otherwise normal brain tissue [45]. Anatomic and physiolopathologic studies suggest that most WMH have a chronically ischemic pathogenesis and are a product of widespread cerebrovascular disease and reduced vascular integrity $[15,16]$. Lacunar infarcts, however, are the product of a subcortical ischemic lesion at the level of a deep perforating artery secondary to an occlusion [46, 47]. Perhaps the ubiquitous presence of WMH present in the vast majority of older non-demented adults are a general marker for cerebrovascular disease, and the relatively less common lacunar infarct is a more specific marker for MCR when present in specific regions like the frontal lobe [14]. WMH are a less specific form of cerebrovascular injury than lacunar infarcts. WMH might also be due to neurodegenerative or age-related changes, which might also explain the lack of significance in their relation to MCR.

Some limitations should be considered.The cross-sectional nature of these data left us unable to establish causality. The design also did not allow us to confirm which participants develop dementia and if so, what subtype of dementia as the cohorts were part of parent studies that do not include longitudinal follow-up assessments. A longitudinal follow up should be included in future studies to track development of dementia and progression of WMH. Smoking history and BMI were not collected in both cohorts. WMH were not measured with an automatic measure that could provide a more objective measure and metric information such as volume; this study's evaluation of WMH was based solely on manual quantification. Lastly, the characterization of MCR is a clinical concept that lacks definitive pathophysiological correlates and biomarkers; it is certainly a consideration that neurodegenerative conditions such as Parkinson's disease or other Parkinsonian syndromes that include motor and cognitive components could contribute to some of the findings in our patient population. For example, a patient in the early 
Table 2: Regional WMH and $\mathrm{MCR}^{1}$.

\begin{tabular}{|c|c|c|c|c|}
\hline & All & NoMCR & MCR & P-value ${ }^{2}$ \\
\hline \multicolumn{5}{|l|}{ French Cohort } \\
\hline $\mathrm{N}$ & 174 & 140 & 34 & \\
\hline $\begin{array}{l}\text { White Matter Hyperintensities } \\
\text { Present }{ }^{4}\end{array}$ & $77.6 \%$ & $80.0 \%$ & $67.7 \%$ & 0.13 \\
\hline Right Frontal & $67.2 \%$ & $69.3 \%$ & $58.8 \%$ & 0.25 \\
\hline Left Frontal & $61.5 \%$ & $62.9 \%$ & $55.9 \%$ & 0.46 \\
\hline Right Parieto-Occipital & $44.3 \%$ & $44.3 \%$ & $44.1 \%$ & 0.99 \\
\hline Left Parieto-Occipital & $47.1 \%$ & $48.6 \%$ & $41.2 \%$ & 0.44 \\
\hline Right Temporal & $7.5 \%$ & $6.4 \%$ & $11.8 \%$ & 0.31 \\
\hline Left Temporal & $5.8 \%$ & $5.0 \%$ & $8.8 \%$ & 0.41 \\
\hline Right Basal Ganglia & $6.9 \%$ & $6.4 \%$ & $8.8 \%$ & 0.63 \\
\hline Left Basal Ganglia & $7.5 \%$ & $8.6 \%$ & $2.9 \%$ & 0.22 \\
\hline Right Cerebellum & $2.3 \%$ & $2.9 \%$ & $0 \%$ & 0.18 \\
\hline Left Cerebellum & $0.6 \%$ & $0.7 \%$ & $0 \%$ & 0.51 \\
\hline Brainstem & $5.2 \%$ & $3.6 \%$ & $11.8 \%$ & 0.08 \\
\hline \multicolumn{5}{|l|}{ Indian Cohort } \\
\hline $\mathrm{N}$ & 184 & 144 & 40 & \\
\hline $\begin{array}{l}\text { White Matter Hyperintensities } \\
\text { Present }^{4}\end{array}$ & $68.5 \%$ & $66.7 \%$ & $75.0 \%$ & 0.31 \\
\hline Right Frontal & $59.8 \%$ & $57.6 \%$ & $67.5 \%$ & 0.26 \\
\hline Left Frontal & $56.0 \%$ & $55.6 \%$ & $57.5 \%$ & 0.83 \\
\hline Right Parieto-Occipital & $45.1 \%$ & $45.1 \%$ & $45.0 \%$ & 0.99 \\
\hline Left Parieto-Occipital & $44.0 \%$ & $45.1 \%$ & $40.0 \%$ & 0.56 \\
\hline Right Temporal & $6.5 \%$ & $6.9 \%$ & $5.0 \%$ & 0.65 \\
\hline Left Temporal & $7.1 \%$ & $8.3 \%$ & $2.5 \%$ & 0.16 \\
\hline Right Basal Ganglia & $6.0 \%$ & $5.6 \%$ & $7.5 \%$ & 0.66 \\
\hline Left Basal Ganglia & $5.4 \%$ & $4.9 \%$ & $7.5 \%$ & 0.53 \\
\hline Right Cerebellum & $0 \%$ & $0 \%$ & $0 \%$ & - \\
\hline Left Cerebellum & $2.7 \%$ & $3.5 \%$ & $0 \%$ & 0.12 \\
\hline Brainstem & $3.3 \%$ & $3.5 \%$ & $2.5 \%$ & 0.75 \\
\hline
\end{tabular}

stages of Parkinson's disease could present with similar features prior to being clinically diagnosed with Parkinson's disease and also have $\mathrm{WMH}[48,49]$. In conclusion, the findings of this study suggest that small vessel disease with risk factors related to MCR other than WMH should be examined. The pathophysiology of MCR remains unclear, but this study is important in that it contributes data to one of the hypotheses. It is reasonable that other vascular risk factors, or combination of risk factors, be investigated further to better understand the mechanism behind the development MCR and find points of potential prevention.

\section{Conflict of Interest}

This research was conducted in the absence of any financial, commercial, or other conflicts of interest.

\section{Acknowledgments}

Joanna L. Mergeche was supported by the Medical Student Training in Aging Research program, National Institute on Aging, American Federation for Aging Research, and Hartford Foundation. This study was supported by the French Ministry of Health (Projet Hospitalier de Recherche Clinique national $n^{\circ}$ 2009-A00533-54) and NIH- National Institute on Aging (R01 AG039330). Gilles Allali was supported by a grant from Geneva University Hospitals and the Baasch-Medicus Foundation and Helena Blumen was supported by a career development grant from NIH- National Institute of Aging (1K01AG049829-01A1). Thank you to Emmeline Ayers for her assistance in data collection and to Dr. Chandrasekharan Kesavadas for his image rating.

\section{References}

1. Varghese J, Wang C, Lipton RB, Holtzer R. 2013. Motoric cognitive risk syndrome and the risk of dementia.J Gerontol A Biol Sci Med Sci 68(4): 412-418. doi: 10.1093/gerona/gls191

2. Ayers E, Verghese J. 2014. Diagnosing motoric cognitive risk syndrome to predict progression to dementia. Neurodegener Dis Manag 4(5): 339342. doi: $10.2217 /$ NMT.14.39

3. Verghese J, Annweiler C, Ayers E, Barzilai N, Beauchet O, et al. 2014. Motoric cognitive risk syndrome: multicountry prevalence and dementia risk. Neurology 83(8): 718-726. doi: 10.1212/WNL.0000000000000717

4. Ayers E, Verghese J. 2016. Motoric cognitive risk syndrome and risk of mortality in older adults. Alzheimers Dement 12(5): 556-564. doi: 10.1016/j.jalz.2015.08.167

5. Barnett JH, Lewis L, Blackwell AD, Taylor M. 2014. Early intervention in Alzheimer's disease: a health economic study of the effects of diagnostic timing. BMC Neurol 14: 101. doi: 10.1186/1471-2377-14101

6. Wimo A, Ballard C, Brayne C, Gauthier S, Handels R, et al. 2014. Health economic evaluation of treatments for Alzheimer's disease: impact of new diagnostic criteria. J Intern Med 275(3): 304-316. doi: 10.1111/joim. 12167

7. Bruandet A, Richard F, Bombois S, Maurage CA, Deramecourt V, et al. 2009. Alzheimer disease with cerebrovascular disease and vascular dementia: clinical features and course compared with Alzheimer disease. J Neurol Neurosurg Psychiatry 80(2): 133-139. doi: 10.1136/jnnp.2007

8. Candelise L, Bianchi F, Galligoni F, Albanese V, Bonelli G, et al. 1984. Italian multicenter study on reversible cerebral ischemic attacks: III-Influence of age and risk factors on cerebrovascular atherosclerosis. Stroke 15: 379-382. doi: 10.1161/01.STR.15.2.379

9. Bogousslavsky J, Regli F, Van Melle G. 1985. Risk factors and concomitants of internal carotid artery occlusion or stenosis. A controlled study of 159 cases. Arch Neurol 42(9): 864-867. doi: 10.1001/ archneur.1985.04060080042014

10. Wilson PW, D'Agostino RB, Levy D, Belanger AM, Silbershatz H, et al. 1998. Prediction of coronary heart disease using risk factor categories. Circulation 97(18): 1837-1847. doi: 10.1161/01.CIR.97.18.1837

11. Ridker PM. 1999. Evaluating novel cardiovascular risk factors: can we better predict heart attacks? Ann Intern Med 130(11): 933-937. doi: 10.7326/0003-4819-130-11-199906010-00018

12. Lewington S, Clarke R, Qizilbash N, Peto R, Collins R. 2002. Agespecific relevance of usual blood pressure to vascular mortality: a metaanalysis of individual data for one million adults in 61 prospective studies. Lancet 360(9349): 1903-1913. doi: 10.1016/S0140-6736(02)11911-8

13. Rooke TW, Hirsch AT, Misra S, Sidawy AN, Beckman JA, et al. 2011. 2011 ACCF/AHA focused update of the guideline for the management of patients with peripheral artery disease (Updating the 2005 Guideline): a report of the American College of Cardiology Foundation/American Heart Association Task Force on practice guidelines. Circulation 124: 2020-2045. doi: 10.1161/CIR.0b013e31822e80c3

14. Wang N, Allali G, Kesavadas C, Noone ML, Pradeep VG, et al. 2016. Cerebral small vessel disease and motoric cognitive risk syndrome: results from the Kerala-Einstein study. J Alzheimers Dis 50(3): 699-707. doi: 10.3233/JAD-150523 
15. Pantoni L, Garcia JH. 1997. Pathogenesis of leukoaraiosis: a review. Stroke 28(3): 652-659. doi: 10.1161/01.STR.28.3.652

16. Young VG, Halliday GM, Kril JJ. 2008. Neuropathologic correlates of white matter hyperintensities. Neurology 71(11): 804-811. doi: 10.1212/01.wnl.0000319691.50117.54

17. Longstreth WT Jr., Manolio TA, Arnold A, Burke GL, Bryan N, et al. 1996. Clinical correlates of white matter findings on cranial magnetic resonance imaging of 3301 elderly people. The Cardiovascular Health Study. Stroke 27(8): 1274-1282. doi: 10.1161/01.STR.27.8.1274

18. Yoshita M, Fletcher E, Harvey D, Ortega M, Martinez O, et al. 2006. Extent and distribution of white matter hyperintensities in normal aging, MCI, and AD. Neurology 67(12): 2192-2198. doi: 10.1212/01. wnl.0000249119.95747.1f

19. Wright CB, Festa JR, Paik MC, Schmiedigen A, Brown TR, et al. 2008. White matter hyperintensities and subclinical infarction: associations with psychomotor speed and cognitive flexibility. Stroke 39(3): 800805. doi: 10.1161/STROKEAHA.107.484147

20. Zheng JJ, Delbaere K, Close JC, Sachdev P, Wen W, et al. 2012. White matter hyperintensities are an independent predictor of physical decline in community-dwelling older people. Gerontology 58(5): 398-406. doi: $10.1159 / 000337815$

21. Zheng JJ, Lord SR, Close JC, Sachdev PS, Wen W, et al. 2012. Brain white matter hyperintensities, executive dysfunction, instability, and falls in older people: a prospective cohort study. J Gerontol A Biol Sci Med Sci 67(10): 1085-1091. doi: 10.1093/gerona/gls063

22. Xiong Y, Wong A, Cavalieri M, Schmidt R, Chu WW, et al. 2014. Prestroke statins, progression of white matter hyperintensities, and cognitive decline in stroke patients with confluent white matter hyperintensities. Neurotherapeutics 11(3): 606-611. doi: 10.1007/ s13311-014-0270-5

23. Rosario BL, Rosso AL, Aizenstein HJ, Harris T, Newman AB, et al. 2016. Cerebral white matter and slow gait: contribution of hyperintensities and normal-appearing parenchyma. J Gerontol A Biol Sci Med Sci 71(7): 968-973. doi: 10.1093/gerona/glv224

24. Kandiah N, Mak E, Ng A, Huang S, Au WL, et al. 2013. Cerebral white matter hyperintensity in Parkinson's disease: a major risk factor for mild cognitive impairment. Parkinsonism Relat Disord 19(7): 680683. doi: 10.1016/j.parkreldis.2013.03.008

25. De Reuck J, Decoo D, Strijckmans K, Lemahieu I. 1992. Does the severity of leukoaraiosis contribute to senile dementia? A comparative computerized and positron emission tomographic study. Eur Neurol 32(4):199-205. doi: 10.1159/000116822

26. Verghese J, Wang C, Lipton RB, Holtzer R, Xue X. 2007. Quantitative gait dysfunction and risk of cognitive decline and dementia. J Neurol Neurosurg Psychiatry 78(9): 929-935. doi: 10.1136/jnnp.2006.106914

27. Verghese J, Noone ML, Johnson B, Ambrose AF, Wang C, et al. 2012. Picture-based memory impairment screen for dementia. J Am Geriatr Soc 60(11): 2116-2120. doi: 10.1111/j.1532-5415.2012.04191.x

28. Nair V, Ayers E, Noone M, Johnson B, Verghese J. 2014. Depressive symptoms and mild cognitive impairment: results from the KeralaEinstein study. J Am Geriatr Soc 62(1): 197-199. doi: 10.1111/jgs.12628

29. Lozano R, Naghavi M, Foreman K, Lim S, Shibuya K, et al. 2012. Global and regional mortality from 235 causes of death for 20 age groups in 1990 and 2010: a systematic analysis for the Global Burden of Disease Study 2010. Lancet 380(9859): 2095-2128. doi: 10.1016/ S0140-6736(12)61728-0

30. Krishnamurthi RV, Feigin VL, Forouzanfar MH, Mensah GA, Connor $\mathrm{M}$, et al. 2013. Global and regional burden of first-ever ischaemic and haemorrhagic stroke during 1990-2010: findings from the Global Burden of Disease Study 2010. Lancet Global health 1(5): e259-281. doi: 10.1016/S2214-109X(13)70089-5

31. Feigin VL, Forouzanfar MH, Krishnamurthi R, Mensah GA, Connor M, et al. 2014. Global and regional burden of stroke during 1990-2010: findings from the Global Burden of Disease Study 2010. Lancet 383 (9913): 245-254.
32. Morris JC, Heyman A, Mohs RC, Hughes JP, van Belle G, et al. 1989. The consortium to establish a registry for Alzheimer's disease (CERAD). Part I. Clinical and neuropsychological assessment of Alzheimer's disease. Neurology 39(9): 1159-1165. doi: 10.1212/ WNL.39.9.1159: 1526-632X

33. Gill TM, Allore HG, Holford TR, Guo Z. 2004. Hospitalization, restricted activity, and the development of disability among older persons. JAMA 292(17): 2115-2124. doi: 10.1001/jama.292.17.2115

34. Rabin LA, Wang C, Katz MJ, Derby CA, Buschke H, et al. 2012. Predicting Alzheimer's disease: neuropsychological tests, self-reports, and informant reports of cognitive difficulties. J Am Geriatr Soc 6(6): 1128-1134. doi: 10.1111/j.1532-5415.2012.03956.x

35. Bilney B, Morris M, Webster K. 2003. Concurrent related validity of the GAITRite walkway system for quantification of the spatial and temporal parameters of gait. Gait Posture 17(1): 68-74. doi: 10.1016/ S0966-6362(02)00053-X

36. Bennett DA, Schneider JA, Buchman AS, Barnes LL, Boyle PA, et al. 2012. Overview and findings from the rush memory and aging project. Curr Alzheimer Res 9(6): 646-663. doi: 10.2174/156720512801322663

37. Wahlund LO, Barkhof F, Fazekas F, Bronge L, Augustin M, et al. 2001. A new rating scale for age-related white matter changes applicable to MRI and CT. Stroke 32(6): 1318-1322. doi: 10.1161/01.STR.32.6.1318

38. Landis JR, Koch GG. 1977. The measurement of observer agreement for categorical data. Biometrics 33(1): 159-174.

39. Liao D, Cooper L, Cai J, Toole JF, Bryan NR, et al. 1996. Presence and severity of cerebral white matter lesions and hypertension, its treatment, and its control. The ARIC Study. Atherosclerosis Risk in Communities Study. Stroke 27(12): 2262-2270. doi: 10.1161/01.STR.27.12.2262

40. Callisaya ML, Beare R, Phan TG, Chen J, Srikanth VK. 2014. Global and regional associations of smaller cerebral gray and white matter volumes with gait in older people. PLoS One 9(1): e84909. doi: 10.1371/ journal.pone.0084909

41. Callisaya ML, Srikanth VK, Lord SR, Close JC, Brodaty H, et al. 2014. Sub-cortical infarcts and the risk of falls in older people: combined results of TASCOG and Sydney MAS studies. Int J Stroke 100: 55-60. doi: $10.1111 /$ ijs. 12279

42. Ithapu V, Singh V, Lindner C, Austin BP, Hinrichs C, et al. 2014. Extracting and summarizing white matter hyperintensities using supervised segmentation methods in Alzheimer's disease risk and aging studies. Hum Brain Mapp 35(8): 4219-4235. doi: 10.1002/hbm.22472

43. Wang L, Leonards CO, Sterzer P, Ebinger M. 2014. White matter lesions and depression: a systematic review and meta-analysis. $J$ Psychiatr Res 56: 56-64. doi: 10.1016/j.jpsychires.2014.05.005

44. Callisaya ML, Beare R, Phan T, Blizzard L, Thrift AG, et al. 2015. Progression of white matter hyperintensities of presumed vascular origin increases the risk of falls in older people. J Gerontol A Biol Sci Med Sci 70(3): 360-366. doi: 10.1093/gerona/glu148

45. Greenberg SM, Vernooij MW, Cordonnier C, Viswanathan A, AlShahi Salman R, et al. 2009. Cerebral microbleeds: a guide to detection and interpretation. Lancet Neurol 8(2): 165-174. doi: 10.1016/S14744422(09)70013-4

46. Lastilla M. 2006. Lacunar infarct. Clin Exp Hypertens 28(3-4): 205-215. doi: $10.1080 / 10641960600549082$

47. Arboix A. 2011. Lacunar infarct and cognitive decline. Expert Rev Neurother 11(9): 1251-1254. doi: 10.1586/ern.11.118

48. Agosta F, Canu E, Stefanova E, Sarro L, Tomic A, et al. 2014. Mild cognitive impairment in Parkinson's disease is associated with a distributed pattern of brain white matter damage. Hum Brain Mapp 35(5): 1921-1929. doi: 10.1002/hbm.22302

49. Compta Y, Buongiorno M, Bargallo N, Valldeoriola F, Munoz E, et al. 2016. White matter hyperintensities, cerebrospinal amyloid-beta and dementia in Parkinson's disease. Nat Rev Neurol 367: 284-290. doi: 10.1038/nrneurol.2011.21 